\title{
New electrolytic bath for electrodeposition of protective binary FeMo and ternary FeMoP films
}

\author{
E.P. Barbano ${ }^{\text {a, b }}$, F.S. Da Silva ${ }^{\text {c }}$, I.A. Carlos ${ }^{\text {b }}$, E. Vallés ${ }^{\text {a, * }}$ \\ ${ }^{a}$ Ge-CPN (Thin Films and Nanostructures Electrodeposition Group), Dpt.Ciència de Materials i Química Física and Institut de Nanociència i Nanotecnologia \\ $\left(I N^{2} U B\right)$, Universitat de Barcelona, Martí i Franquès 1, 08028, Barcelona, Spain \\ ${ }^{\mathrm{b}}$ Departamento de Química, Universidade Federal de São Carlos, CP 676, 13565-905, São Carlos, SP, Brazil \\ c Instituto de Química, UNESP-Univ. Estadual Paulista, Departamento de Físico-Química, Rua Prof. Francisco Degni, 55, 14800-060, PO. Box 335, Araraquara, \\ Sp, Brazil
}

\section{A R T I C L E I N F O}

\section{Article history:}

Received 23 August 2016

Received in revised form

20 October 2016

Accepted 22 October 2016

Available online 24 October 2016

\section{Keywords:}

Electrodeposition

Iron-molybdenum alloys

Phosphorous

Amorphous coatings

\begin{abstract}
A B S T R A C T
FeMoP coatings with promising corrosion resistance properties were performed by using trisodiumnitrilotriacetate(NTA) as chelating agent for Fe(III). The versatility of the bath to obtain uniform and protecting coatings over different substrates has been tested. The mechanism of electrodeposition of FeMoP is the same than that of the FeMo one; over the different substrates tested, the Fe(III) complex reduces to $\mathrm{Fe}(\mathrm{II})$, which, after some molybdenum oxide formation, catalyses the molybdenum oxides reduction, leading to the binary FeMo or ternary FeMoP coatings. The incorporation of $\mathrm{P}$ in the amorphous films (which implies a reduction of the grain size in the compact and uniform deposits) with significant molybdenum percentage induces an improvement of the corrosion resistance properties. The FeMoP coatings are promising coatings for corrosion resistance, with much lower environmental impact than hard chromium or cobalt-base films.
\end{abstract}

(C) 2016 Elsevier B.V. All rights reserved.

\section{Introduction}

Molybdenum containing alloys have been proposed as improved materials respect to pure $\mathrm{Fe}$, Co and $\mathrm{Ni}$ coatings for different applications, because molybdenum modulates the magnetic properties of the ferromagnetic metals [1], the corrosion resistance or the hardness of the coatings [2] and confers catalytic properties for determined reactions [3,4]. The mechanism of MMo electrodeposition ( $\mathrm{M}=\mathrm{Fe}, \mathrm{Co}, \mathrm{Ni}$ ), which occurs trough induced codeposition, has been studied over different substrates [5-8] using electrolytic baths containing citrate and boric.

On the other hand, the introduction of $\mathrm{P}$ in different metallic films usually improves the characteristics of the deposits $[9,10]$. Therefore, nanocrystalline CoP alloys have been proposed for the replacement of electro-plated hard chromium coatings in the aeronautic industry $[11,12]$. For iron or iron-based alloys, a low proportion of $\mathrm{P}$ in metallic deposits induces a nanocrystallinity of the deposits and, therefore, an improvement of the corrosion resistance, magnetic and catalytic properties, hardness and

\footnotetext{
* Corresponding author.

E-mail address: e.valles@ub.edu (E. Vallés).
}

ductility of the metal or alloy films [9-15].

Binary FeMo films have been proposed as catalysts for methanol oxidation [16] or hydrogen electrogeneration [17]. In these works, significant molybdenum percentage in the alloy was attained in order to enhance the catalytic properties, but the preparation method implies mixing methods or electrodeposition ones in aggressive sodium hydroxide solution. We propose here 1) the electrochemical synthesis of both FeMo and FeMoP films over different substrates, by analyzing the versatility of the electrolytic bath selected 2) the preparation of uniform binary and ternary films that present a good corrosion resistance, in order to extend the applicability of the iron molybdenum based coatings. The interest is the use of a stable electrolytic bath, containing anions that can't be reduced during the coating formation, with alkaline $\mathrm{pH}$ in order to minimize simultaneous hydrogen evolution, with much lower environmental impact that hard chromium or cobalt alloys baths, for synthesized protecting coatings of different metallic materials. The alloy of iron with molybdenum and phosphorous is proposed due to the chemical resistance and low pitting tendency [18].

Some authors have prepared FeMo coatings by means of electrodeposition [19-21] from acidic citrate solutions, but the use of these electrolytic baths implies some simultaneous reduction of 
both citrate and protons, as the manner that the deposits can result carbonated and hydrogenated. FeMo, FeMoP and FeWP electrodeposition baths containing NTA (Nitrilotriacetic acid trisodium salt monohydrate) as complexing agent to $\mathrm{Fe}(\mathrm{III})$ ion were proposed by Carlos et al. [22,23] as an alternative to citrate anions, which can be reduced at the cathode, leading to decomposition of the bath, as reported previously. Potentiometric studies showed that these baths were stable at $\mathrm{pH} \sim 8$ and that the formation of FeMo and FeW based alloys is possible over noble metal (platinum electrode). From these preliminary studies, the aim of the present work is to test the versatility of the proposed alkaline bath, containing NTA as complexing agent, to electrodeposit FeMo and FeMoP coatings over different types of substrates, in order to obtain compact, uniform, non-cracked deposits with a good corrosion resistance. P incorporation should improve the corrosion resistance of the deposits, favouring its nanocrystallinity or amorphous structure.

\section{Experimental}

The proposed electrochemical baths to perform FeMo and FeMoP electrodeposition consists in $0.033 \mathrm{M} \mathrm{FeCl}_{3} \cdot 6 \mathrm{H}_{2} \mathrm{O}+$ $0.0385 \mathrm{M} \mathrm{Na}_{2} \mathrm{MoO}_{4} \cdot 2 \mathrm{H}_{2} \mathrm{O}+0.176 \mathrm{M}$ NTA (FeMo bath) and $0.033 \mathrm{M}$ $\mathrm{FeCl}_{3} \cdot 6 \mathrm{H}_{2} \mathrm{O}+0.0385 \mathrm{M} \mathrm{Na} 2 \mathrm{MoO}_{4} \cdot 2 \mathrm{H}_{2} \mathrm{O}+\mathrm{x} \mathrm{Na} \mathrm{H}_{2} \mathrm{PO}_{2} \cdot 6 \mathrm{H}_{2} \mathrm{O}$, with $\mathrm{x}=0.0165 \mathrm{M}$ (FeMoP-1 bath) and $\mathrm{x}=0.0495 \mathrm{M}$ (FeMoP-2 bath). The $\mathrm{pH}$ of each solution was adjusted down to 8.0 with $\mathrm{HCl}$. All the reagents were of analytical grade and the water was purified by means of a Millipore MilliQ system. Fe(III) salt was selected in order to improve the durability of the bath respect to solutions containing $\mathrm{Fe}(\mathrm{II})$. NTA at alkaline $\mathrm{pH}$ was selected as an alternative to acidic citrate solutions; the NTA has a similar structure that Ethylenediaminetetraacetic acid (EDTA), used in Ag-Zn [24], Zn-Fe [25] or $\mathrm{Zn}-\mathrm{Cu}$ [26] electrodeposition. At the selected $\mathrm{pH}$, good solubility of the different components is attained and the simultaneous hydrogen evolution during the electrodeposition is minimized.

Speciation study using the Hydra-Medusa software [27] was performed for the selected concentrations in order to know the electroactive species at the solution $\mathrm{pH}$.

Different working electrodes have been selected: $\mathrm{Cu}$ and graphite disks $\left(0.5 \mathrm{~cm}^{2}\right)$, steel disk $\left(0.78 \mathrm{~cm}^{2}\right)$ and $\mathrm{Si} / \mathrm{Ti}(15 \mathrm{~nm}) / \mathrm{Cu}$ $(100 \mathrm{~nm})$ substrates $\left(0.25 \mathrm{~cm}^{2}\right)$. A Pt plate and a $\mathrm{Ag} / \mathrm{AgCl}$, $3.0 \mathrm{~mol} \mathrm{~L}^{-1} \mathrm{KCl}$ electrode, $\mathrm{E}^{0}=0.210 \mathrm{~V}$, with an appropriate Luggin capillary, were employed as auxiliary and reference electrodes, respectively.

Voltammetric studies and potentiodynamic curves were recorded with a microcomputer-controlled AUTOLAB potentiostat/galvanostat PGSTAT 30 equipment and processed with GPES software. All experiments were carried out at room temperature $\left(25.0^{\circ} \mathrm{C}\right)$. Field-emission Scanning Electron Microscope (SEM) photographs were obtained with JEOL JSM 6510 equipment. Semi-quantitative chemical analysis of the electrodeposits was performed by means of Energy-Dispersive X-ray Spectroscopy (EDS), by using Oxford Microanalysis System INCA software. Corrosion resistance experiments were performed in non-deoxygenated $0.1 \mathrm{M} \mathrm{Na}_{2} \mathrm{SO}_{4}$ solutions at $(25 \pm 1){ }^{\circ} \mathrm{C}$. Impedance measurements were carried out using a conventional Tait [28] type three-electrode cell with $80 \mathrm{~mL}$ electrolyte solution. Sodium sulphate has been selected for corrosion test experiments in order to evaluate the generalized corrosion of the deposited films, avoiding the pitting effect of the chloride ions on the coating. Coated substrates were used as working electrodes, and they were fixed at the bottom of the electrochemical cell. The counter electrode was a Pt grid, and the potentials were referred to an aqueous $\mathrm{Ag} / \mathrm{AgCl} / \mathrm{KCl} 3 \mathrm{M}$ reference electrode connected to the working solution through a Luggin capillary.

The corrosion resistance of samples was evaluated by polarization curves, open circuit potential $\left(E_{\mathrm{OCP}}\right)$ measurements, Tafel experiments and electrochemical impedance spectroscopy (EIS). Potentiodynamic polarizations were performed after $E_{\mathrm{OCP}}$ monitoring with a minimum of $2 \mathrm{~h}$ until attaining the steady-state potential $\left(E_{s s}\right)$. A scan rate of $0.1 \mathrm{mV} / \mathrm{s}$ beginning at -0.300 to $+0.300 \mathrm{~V}$ vs. $E_{S S}$ was used. EIS and $E_{\mathrm{OCP}}$ were monitored from $1 \mathrm{~h}$ until $48 \mathrm{~h}$ of immersion. EIS measurements were performed in the frequency range from $100 \mathrm{kHz}$ to $5 \mathrm{mHz}$, by applying a sinusoidal potential perturbation of $10 \mathrm{mV}$ rms on $E_{O C P}$ with 10 points/frequency decade. Tafel experiments were performed in the AUTOLAB equipment. All EIS experimental data were tested for consistency with the Kramers-Kronig transform and only those points that passing in the test are presented and discussed in the paper. For quantitative analysis of the EIS responses, the Electrical Equivalent Circuit (EEC) theory using the Z-view ${ }^{\circledR}$ program was employed.

XRD patterns were recorded with $\mathrm{Cu} \mathrm{K} \alpha$ radiation $(1.5406 \AA)$, using a X-ray generator equipped with a goniometer, in $2 \theta$ scanning mode (from $2 \theta=10.0^{\circ}$ to $120.0^{\circ}$ in steps of $0.033^{\circ}$ and a time per step of $600 \mathrm{~s})$.

\section{Results and discussion}

\subsection{Electrodeposition process steps}

The electrodeposition process of the FeMo and FeMoP systems has been investigated mainly on copper substrates, in order to minimize hydrogen evolution during the deposition, although studies on graphite or steel have been also performed to generalize the different stages of the process and the characteristics of the coatings.

In order to define the potential range to induce the formation of the alloy deposits, voltammetric study was performed. Cyclic voltammetry of blank solution ( $B$ bath), blank solution containing the complexing agent (B-NTA bath), iron-NTA solution (Fe-NTA bath), FeMo-NTA solution (FeMo bath) and FeMoP-NTA solution (FeMoP-1 bath) (Table 1) were recorded and compared to identify the different peaks and to detect the stages of the electrodeposition processes. Additional experiments in graphite or steel substrates have been also performed to generalise the deposition process and clearly identify some of the reduction peaks.

Blank solution ( $B$ bath) on a copper electrode shows the onset of the water reduction at around $-1.4 \mathrm{~V}$ and the copper oxidation, in the anodic branch, at $0.2 \mathrm{~V}$ (Fig. $1 \mathrm{a}$, continuous line). When the complexing agent was added to the solution (B-NTA bath), a reduction peak was detected $(-1.3 \mathrm{~V})$ of the initial reductive atomic hydrogen formation, before massive water reduction (Fig. 1a, dashed line). In the anodic scan, an oxidation peak at $-0.2 \mathrm{~V}$ is observed, of some molecular hydrogen retained on the electrode, before the copper oxidation, that now is advanced. In Fig. 1b the increase of the anodic peak when the cathodic limit is more negative is detected; also, this oxidation peak is not detected when the potential was scanned from the start potential to positive values or when solution is stirring during the scan, corroborating the assignation of molecular hydrogen adsorption.

The solution containing the $\mathrm{Fe}(\mathrm{III})$ salt in the presence of NTA ( $\mathrm{Fe}-\mathrm{NTA}$ bath), and therefore the $\left[\mathrm{Fe}(\mathrm{NTA})_{2}\right]^{3-}$ complex accordingly to the speciation study [22], shows a first reduction current from the start potential $(-0.2 \mathrm{~V})$, assigned to the $\mathrm{Fe}(\mathrm{III}) / \mathrm{Fe}(\mathrm{II})$ process, and posterior iron deposition, simultaneous to massive hydrogen evolution at very negative potentials (Fig. 2 , dotted line). In the anodic scan, the peak corresponding to the oxidation of iron deposit is observed at around $-0.9 \mathrm{~V}$. When the solution contains also the molybdate salt (FeMo-bath), a new reduction peak (proposed as molybdate reduction) appears after the $\mathrm{Fe}(\mathrm{III}) / \mathrm{Fe}(\mathrm{II})$ stage, and the deposition process, now of the FeMo induced codeposition, advanced (Fig. 2, dashed line). A new oxidation peak, at 
Table 1

Composition of the electrolytic baths used during the study. In all cases, the solution's pH is 8 .

\begin{tabular}{|c|c|c|c|c|c|c|}
\hline Electrolytic bath & {$[\mathrm{NaCl}] / \mathrm{M}$} & {$\left[\mathrm{Na}_{2} \mathrm{SO}_{4}\right] / \mathrm{M}$} & {$\left[\mathrm{FeCl}_{3}\right] / \mathrm{M}$} & {$\left[\mathrm{Na}_{2} \mathrm{MoO}_{4}\right] / \mathrm{M}$} & {$[\mathrm{NTA}] / \mathrm{M}$} & {$\left[\mathrm{Na}_{2} \mathrm{H}_{2} \mathrm{PO}_{2}\right] / \mathrm{M}$} \\
\hline$B$ & 0.0099 & 0.0385 & & & & \\
\hline$B-N T A$ & 0.0099 & 0.0385 & & & 0.176 & \\
\hline $\mathrm{Fe}-\mathrm{NTA}$ & & 0.0385 & 0.0033 & & 0.176 & \\
\hline FeMo & & & 0.0033 & 0.0385 & 0.176 & \\
\hline FeMoP-1 & & & 0.0033 & 0.0385 & 0.176 & 0.0165 \\
\hline $\mathrm{FeMoP}-2$ & & & 0.0033 & 0.0385 & 0.176 & 0.0495 \\
\hline
\end{tabular}
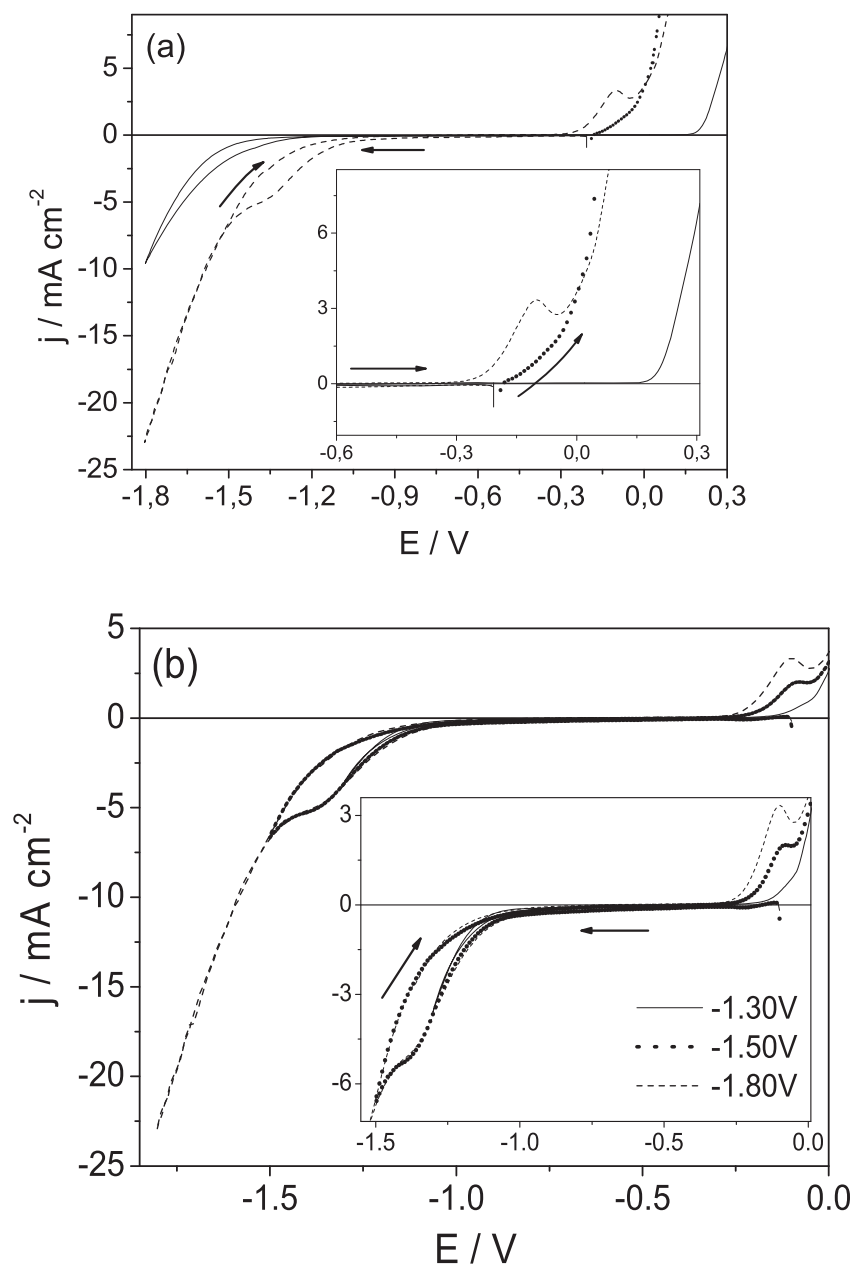

Fig. 1. Voltammetric curves at $10.0 \mathrm{mV} \mathrm{s}^{-1}$ on copper substrate of (a) B solution (solid line), $B-N T A$ solution (dashed line-starting with cathodic scan, dotted line-starting with anodic scan); (b), $B$-NTA solution, effect of the final deposition potential $\left(\mathrm{E}_{\mathrm{f}}\right)$ : $-1.30 \mathrm{~V}$ (solid line), $-1.50 \mathrm{~V}$ (dotted line) and $-1.80 \mathrm{~V}$ (dashed line).

around $-0.4 \mathrm{~V}$, appeared. We propose that this peak corresponds to the FeMo alloy oxidation. The shift of the FeMo oxidation peak respect to the Fe oxidation one in the voltammetry allows to expect the more difficulty of the alloy oxidation respect to the pure metal (Fe) one. Fig. 3a demonstrates that alloy formation only occurs after the molybdate reduction peak and we assign, therefore, in the FeMo bath, the first reduction peak (C1) to $\mathrm{Fe}(\mathrm{III}) / \mathrm{Fe}(\mathrm{II})$, the following peak (C2) to molybdate reduction and posterior reduction current to simultaneous Fe deposition, induced Mo deposition and, consequently, FeMo alloy formation.

The incorporation of the phosphorous salt (FeMoP-1 bath) did not significantly modify the voltammetry profile (Fig. 3b), which indicates a similar deposition stages in the P-containing solution.

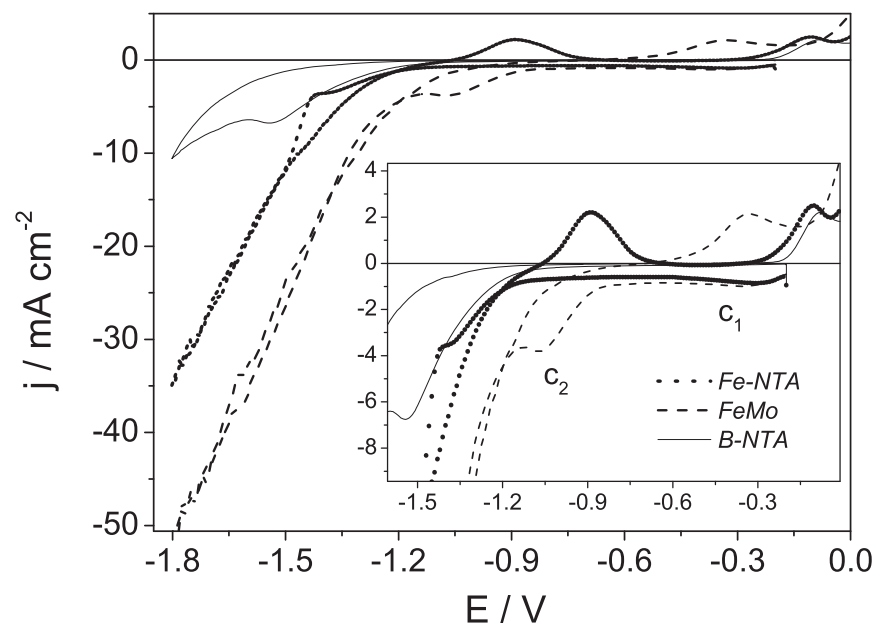

Fig. 2. Voltammetric curves at $10.0 \mathrm{mV}^{-1}$ on copper substrate in:B-NTA solution (solid line), $\mathrm{Fe}-\mathrm{NTA}$ solution (dotted line) and FeMo solution (dashed line).

In order to corroborate the assignation of the $\mathrm{C} 1$ peak to the $\mathrm{Fe}(\mathrm{III}) / \mathrm{Fe}(\mathrm{II})$ reduction process, graphite electrode was used. In Fig. 4, the oxidation peak of $\mathrm{Fe}(\mathrm{II})$ to $\mathrm{Fe}(\mathrm{III})$ is clearly seen, completing the typical profile of the $\mathrm{Fe}(\mathrm{III}) / \mathrm{Fe}(\mathrm{II})$ couple.

Lastly, the voltammetry study of both FeMo and FeMoP baths systems demonstrates that the different stages of the alloy electrodeposition process are the same over different substrates (Fig. 5).

After defining the different potential zones in the voltammetry study, potentiostatic reduction was performed to detect and identify the possible deposits in each potential zone. A charge density in the range $5-100 \mathrm{Ccm}^{-2}$ was applied. Fig. 6 shows the chronoamperometric reduction curves at three potentials: $-0.4 \mathrm{~V}$ (in the $\mathrm{C} 1$ peak), $-1.1 \mathrm{~V}$ (in the $\mathrm{C} 2$ peak) and $-1.8 \mathrm{~V}$ (at potentials more negative than $\mathrm{C} 2$ peak) and the corresponding SEM images of the electrode after the reduction. The SEM pictures of the electrode after the reduction and the EDX analysis of the electrode surface demonstrates that deposit was not formed at potentials assigned to the $\mathrm{Fe}(\mathrm{III}) / \mathrm{Fe}(\mathrm{II})$ reduction because $\mathrm{Fe}$ and Mo were undetected. However, a cracked flat morphology, typical of electrodeposited molybdenum oxides [29] forms at potentials in the C2 zone, corroborated by the detection by means of EDX of only molybdenum and oxygen. Finally, the reduction at potentials more negative than those of the peak C2 leads to FeMo nodular compact deposits, in which Fe and Mo were clearly detected.

\subsection{Preparation and characterization of FeMo and FeMoP deposits}

Defined the potential zone in which FeMo and FeMoP deposits can be formed, the influence of the substrate and deposit's thickness on the properties of the films has been analysed. Different configuration of the electrodes was used as a function of the type of substrate: When copper, steel or graphite electrodes were used; the metal or graphite rod was embedded in a Teflon support and placed 

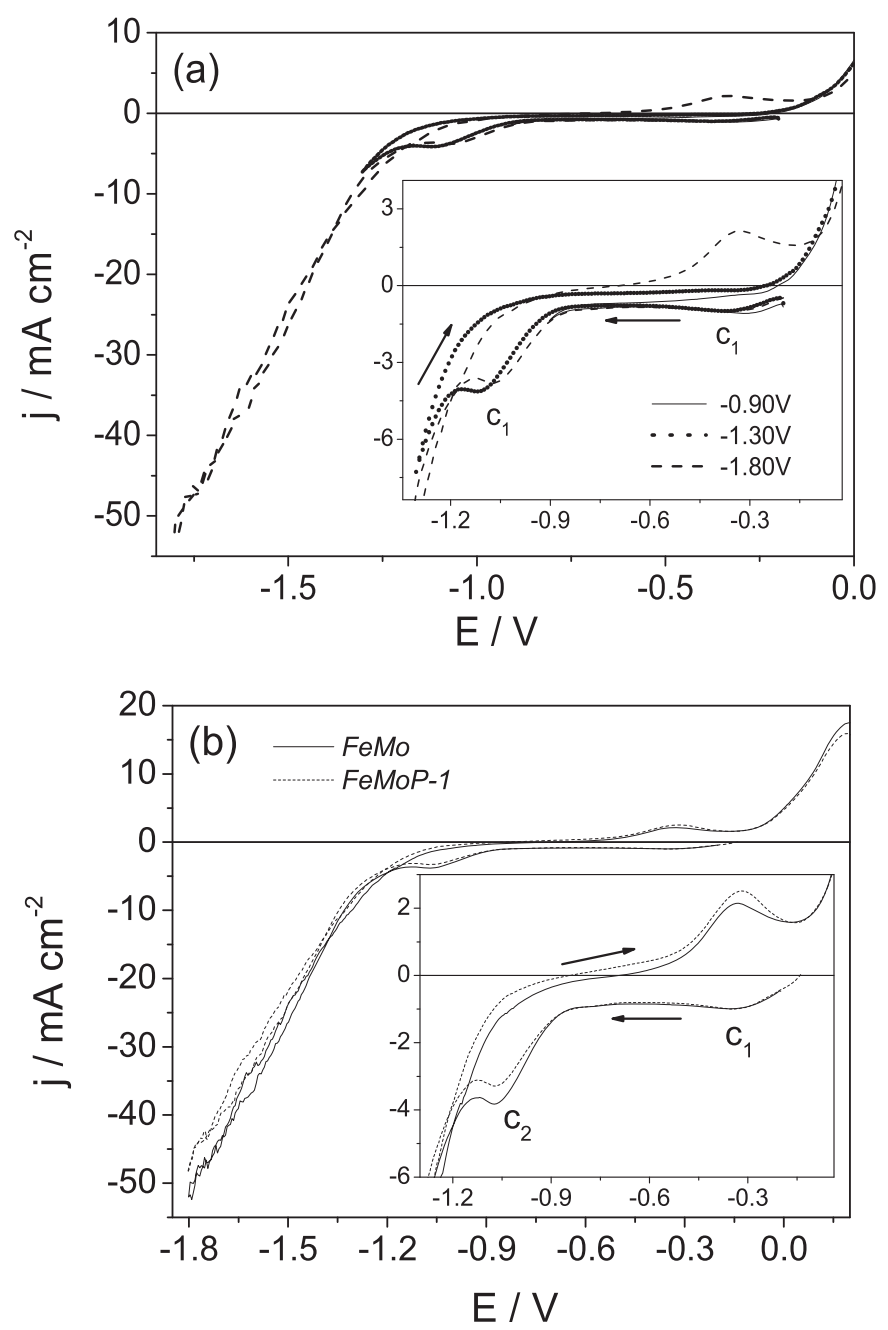

Fig. 3. Voltammetric curves at $=10.0 \mathrm{mV}^{-1}$ on copper substrate in: (a) FeMo bath effect of the final deposition potential $\left(E_{\mathrm{f}}\right):-0.90 \mathrm{~V}$ (solid line), $-1.30 \mathrm{~V}$ (dotted line) and $-1.80 \mathrm{~V}$ (dashed line); (b) FeMo bath (solid line) and FeMoP-1 bath (dashed line).

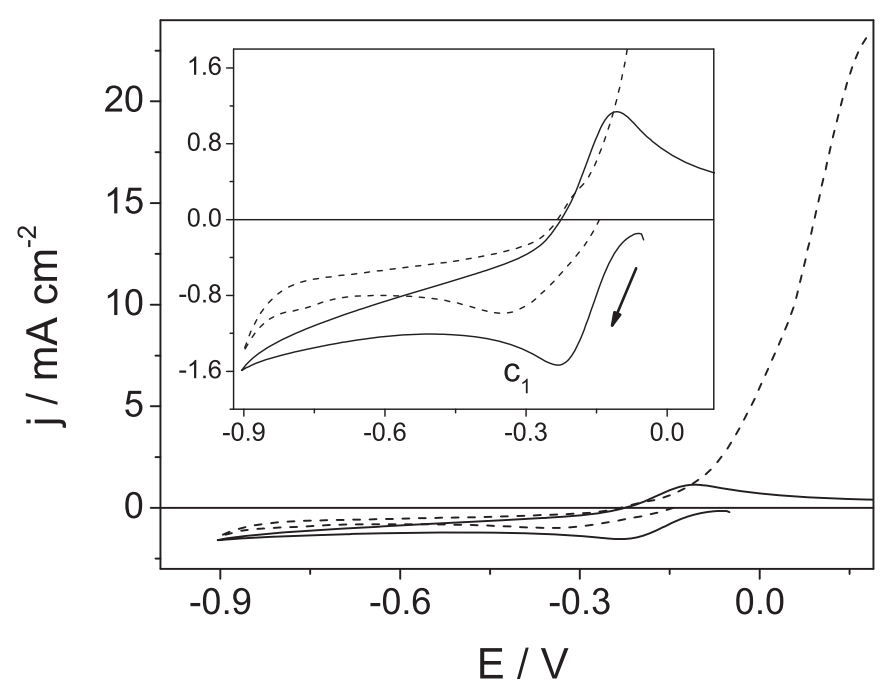

Fig. 4. Voltammetric curves at $10.0 \mathrm{mV}^{-1}$ in FeMo bath performed on copper (dashed line) and graphite substrate(solid line). in parallel to the solution surface, either in the top or in the bottom of the solution. However, when $\mathrm{Si} / \mathrm{Ti} / \mathrm{Cu}$ pieces were used as substrates, they were placed perpendicularly to the solution surface. Similar deposits were obtained in all case, although in the parallel configuration small hydrogen bubbles (formed as a consequence of some simultaneous hydrogen evolution) were more easily retained than in the perpendicular configuration.

Figs. 7 and 8 show representative chronoamperometric curves of the binary and ternary iron alloys electrodeposition for two of the substrates selected and the corresponding morphology of the deposits prepared. Similar shape of the chronoamperometric curves was observed for FeMo or FeMoP electrodeposition. After the nucleation and growth stage, current density gradually increases as a consequence of an increase in the roughness of the deposits. Table 2 shows the composition of the deposits prepared at different potentials (from $-1.3 \mathrm{~V}$ to $-1.8 \mathrm{~V}$ ) on the substrates tested; from the values obtained we can extract the following conclusions: 1) FeMo and FeMoP coatings can be formed over different substrates at potentials more negative than the peak C2; 2) Low variation of the deposits composition as a function of the potential applied is observed, which favours the proposal of the NTA selected bath to be applied in industrial conditions; in all cases the deposits contain significant molybdenum percentage, with an average stoichiometry of $\mathrm{FeMo}_{0.6} ; 3$ ) the deposits between 1 and $4 \mu \mathrm{m}$ (charge density $100-500 \mathrm{Ccm}^{-2}$ ) maintain its composition, and 4 ) the composition obtained, for a fixed potential, is low dependent of the substrate; only in the case of steel substrates, an increase of the iron percentage respect to that of the other substrates is obtained, probably as a consequence of the greater affinity between the iron-containing coating and the substrate, which can favour the iron deposition. Moreover, the electrodeposition allowed incorporating phosphorous in the alloy and the P percentage in the deposits can be increased as the hypophosphite concentration increases. The P presence leads to an improvement in the morphology uniformity and a decrease in the grain size for moderate deposition charges (corresponding to deposits until $5 \mu \mathrm{m}$ ). However, a drastic increase of the deposition charge leads to less uniform and more dendritic coatings. Similar uniform deposits, rich in molybdenum, can be obtained over different substrates $(\mathrm{Cu}$, $\mathrm{Si} / \mathrm{Ti} / \mathrm{Cu}$, graphite, steel) which will allow the use of the proposed electrolytic bath over several nature of metallic pieces.

The crystalline structure of the deposits was analysed by means of X-Ray diffraction experiments in order to complete the deposits characterization and interpretation of the corrosion tests. The structural characterization was difficult when deposits were prepared over rod substrates of platinum, copper, steel or graphite, because the diffraction peaks of the own substrates masks the deposit profile. For this, $\mathrm{Si} / \mathrm{Ti}(10 \mathrm{~nm}) / \mathrm{Cu}(100 \mathrm{~nm})$ pieces were also used to prepare the alloy deposits in order to minimize the deposit/ substrate ratio. Fig. 9 shows that similar deposits, both in morphology and composition were obtained for the same deposition potential applied. Therefore, high deposition charge (500 $\mathrm{C} \mathrm{cm}^{-2}$ ) and $\mathrm{Si} / \mathrm{Ti} / \mathrm{Cu}$ substrates were selected to characterize the crystalline structure of both FeMo and FeMoP films.

The X-ray diffractograms of both FeMo and FeMoP deposits present mainly the peaks corresponding to the (111) and (222) reflections of the copper seed layer (observed peaks at 43 and $95.5^{\circ}$ $2 \theta$ ), which indicates that the copper seed layer present a clear preferred orientation, the titanium peaks (at diffraction angles lower than $40^{\circ} 2 \theta$, and the silicon peak at around $70^{\circ} 2 \theta$ (Fig. 9, upper part). No clear peaks assigned to the alloy coatings are observed, even the high thickness of the deposit respect to that of the seed layer, which allows proposing the formation of noncrystalline deposits. However, the presence of the coating justifies the high background in the diffractograms respect to those of the 


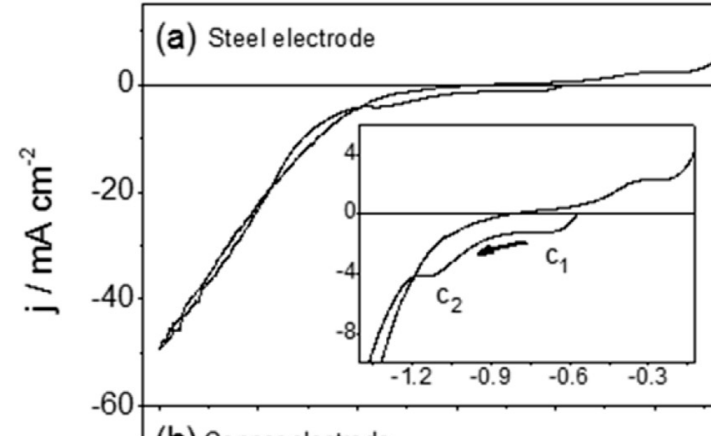

(b) Copper electrode

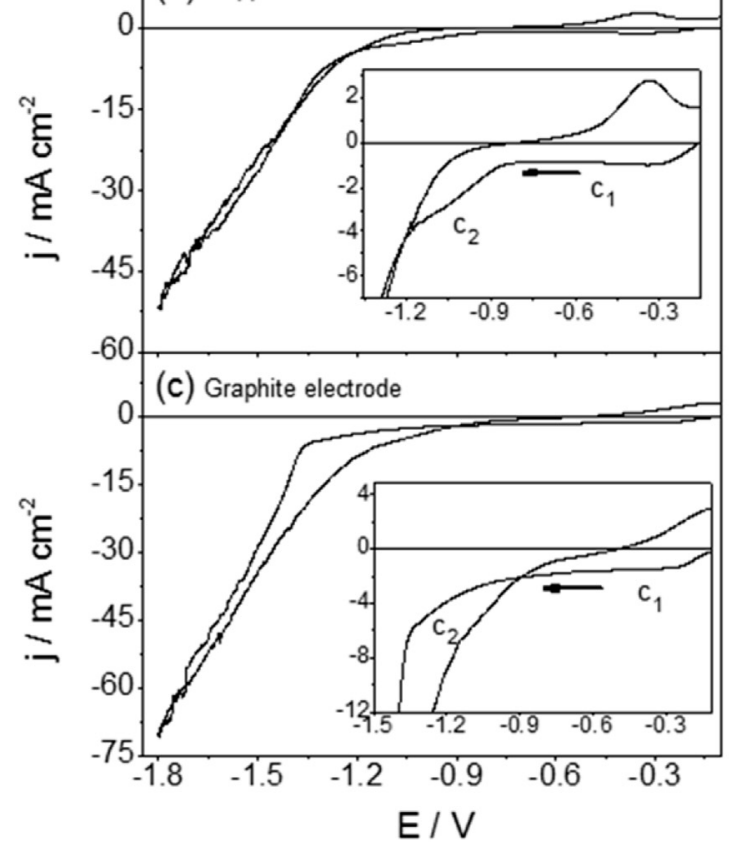

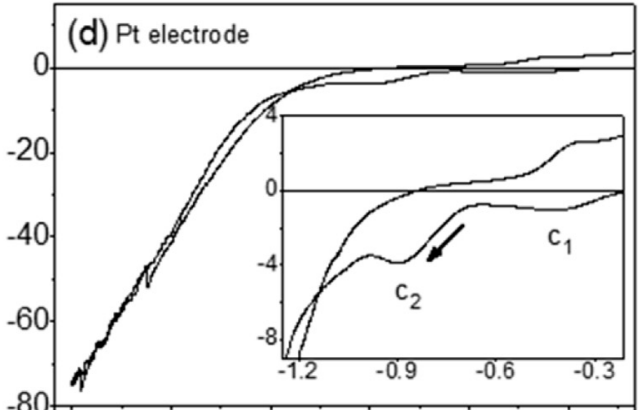

(e) SiTiCu electrode

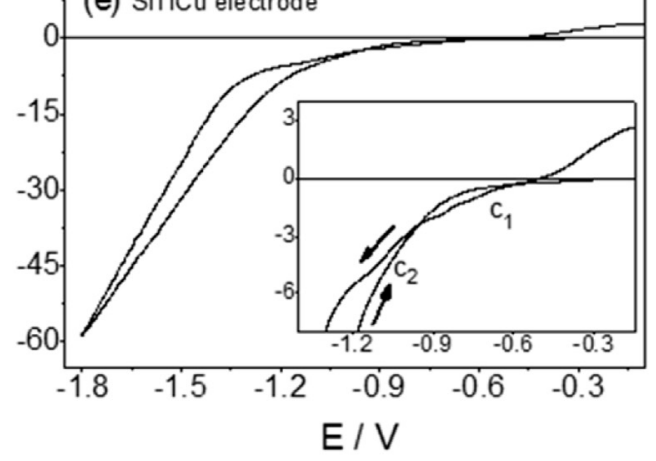

Fig. 5. Voltammetric curves at $=10.0 \mathrm{mV}^{-1}$ on different substrates in FeMoP-2 bath: (a) steel; (b) copper; (c) graphite; (d) platinum and (e) Si/Ti/Cu.

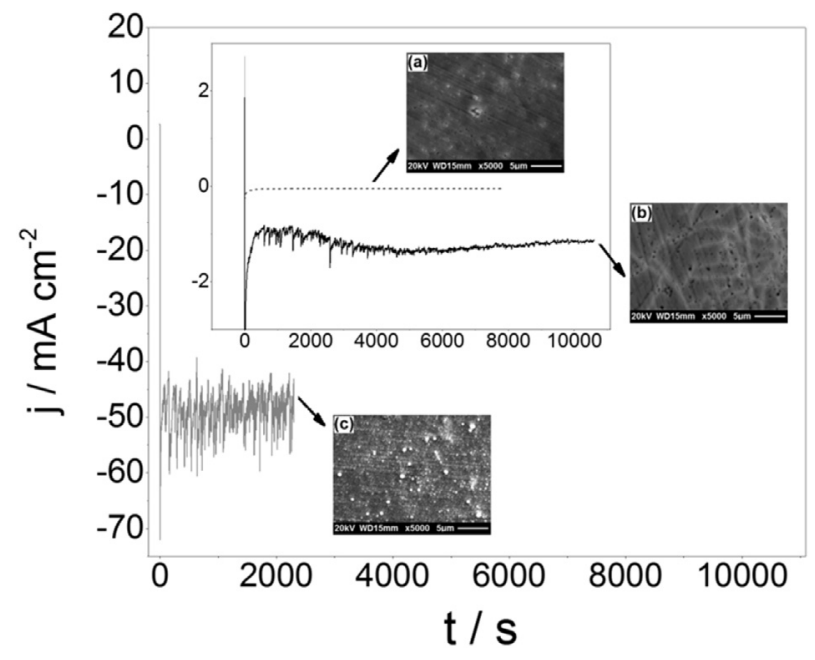

Fig. 6. SEM micrographs and EDX composition for FeMo bath in Copper substrate of FeMo electrodeposits obtained at (a) $-0.40 \mathrm{~V}, \mathrm{q}_{\mathrm{d}} 5 \mathrm{Ccm}^{-2}$; (b) $-1.10 \mathrm{~V}, \mathrm{q}_{\mathrm{d}} 20 \mathrm{Ccm}^{-2}$ and (c) $-1.80 \mathrm{~V}, \mathrm{q}_{\mathrm{d}} 100 \mathrm{Ccm}^{-2}$.

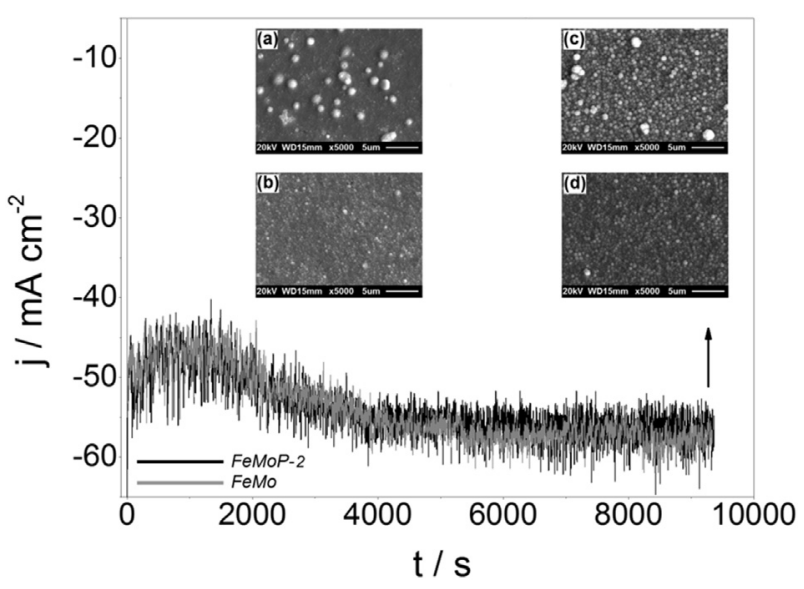

Fig. 7. SEM micrographs and EDX composition of deposits obtained at $-1.8 \mathrm{~V}$ in FeMo bath ((a) $100 \mathrm{Ccm}^{-2}$, (c) $500 \mathrm{Ccm}^{-2}$ ) FeMoP-2 bath ((b) $100 \mathrm{Ccm}^{-2}$, (d) $500 \mathrm{Ccm}^{-2}$ ) over steel substrate. 


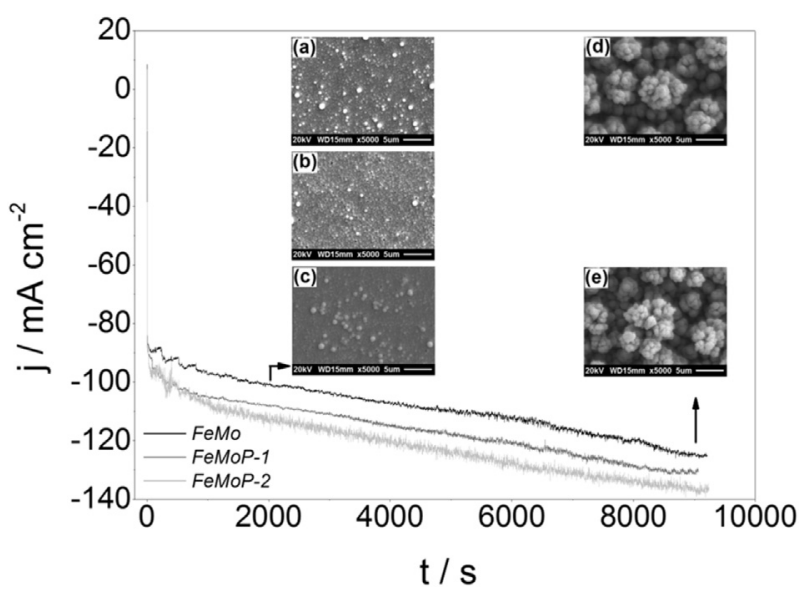

Fig. 8. Chronoamperometric curves, at $-1.8 \mathrm{~V}$ on $\mathrm{Si} / \mathrm{Ti} / \mathrm{Cu}$ substrates, of the electrodeposition in FeMo (black line), FeMoP-1 (dark grey line) and FeMoP-2 baths (grey line). SEM images and composition of the deposits obtained at charge density of $100 \mathrm{Ccm}^{-2}$ ((a), (b) and (c)) and $1000 \mathrm{Ccm}^{-2}((\mathrm{~d}),(\mathrm{e}))$.

substrate, as a consequence of the iron absorption. Amorphous signal is detected as a wide band partially masked by the presence of the (111) peak of copper. In order to corroborate the presence of a wide band corresponding to the FeMo and FeMoP amorphous coatings, X-ray diffractograms of two copper pieces, before and after the electrochemical deposition of the FeMo and FeMoP coatings were recorded, with high statistics, in the $30-110^{\circ} 2 \theta$ range. A full profile analysis of the experimental data in the 30-60 $2 \theta$ range was performed using pseudo-Voight functions, by considering the presence of three diffraction peaks in this ${ }^{\circ} 2 \theta$ range for the deposited films: the peaks 111 and 200 of the copper substrate and a wide peak assigned to the coatings. The parameters of the adjusted peaks in the X-ray profiles of the substrate before the deposition were used to adjust the X-ray profile when the coating was formed on the substrate. Fig. 9 (lower part) shows the good concordance of the experimental and adjusted profiles taking into account the presence of a wide band assigned to the amorphous coatings, both in FeMo (A) and in FeMoP (B) deposits.

\subsection{Corrosion tests}

\subsubsection{Potentiodynamic polarization}

From the potentiodynamic curves, corrosion potential ( $E_{\text {corr }}$ ) and current density corrosion $\left(\mathrm{j}_{\text {corr }}\right)$ were evaluated. The protocol for corrosion resistance analysis has been carefully selected in order to obtain the more adequate response. Different replicas of the assays were performed in each condition.

Fig. 10 shows representative potentiodynamic curves, in logarithmic form, of the FeMo and FeMoP coatings prepared on $\mathrm{Si} / \mathrm{Ti} / \mathrm{Cu}$ substrates. The presence of $\mathrm{P}$ in the deposits shifts the corrosion curves to less negative potentials, improving the corrosion resistance. The anodic part of the curves reveals some passivation of the surface in the ternary alloy, as a consequence of the superficial oxides formation. Table 3 shows the promising values of $\mathrm{E}_{\mathrm{corr}}$ and $\mathrm{j}_{\text {corr }}$ in each case. The P-containing alloy really enhances the corrosion resistance tendency.

\subsubsection{Long term immersion test}

To further evaluate the long-term corrosion resistance of deposits electrochemically prepared, the changes in EOCP and EIS characteristics as a function of immersion time were carried out. $E_{\mathrm{OCP}}$ of the substrate (not shown) was $0.01 \mathrm{~V}$ in the first hour of immersion, stabilizing after $24 \mathrm{~h}$ of immersion, at $0.03 \mathrm{~V}$ (Fig. 11). This slight potential increase is assigned to the formation of copper oxides on the surface of the material [30]. EOCP behavior of the coatings was completely different from the substrate. At $1 \mathrm{~h}$ of immersion the potential values were $E_{\mathrm{OCP}}=-0.49 \mathrm{~V}$ (FeMo) and $E_{\mathrm{OCP}}=-0.46 \mathrm{~V}$ (FeMoP), slightly more positive for the FeMoP coating, which suggest the improvement of the coating by introduction of some phosphorous in the deposits. The evolution of the $E_{\mathrm{OCP}}$ with the immersion time in the test solution reveal low change (especially for the FeMoP coating) from 2 to $10 \mathrm{~h}$ of immersion. After that, the value gradually evolves $\left(E_{\mathrm{OCP}}=-0.13 \mathrm{~V}\right.$ (FeMo) and $E_{\mathrm{OCP}}=-0.04 \mathrm{~V}$ (FeMoP) after $24 \mathrm{~h}$, and finally to $0.03 \mathrm{~V}$ after $48 \mathrm{~h}$ of immersion) to the value corresponding to that of the substrate. This indicates that coatings has slightly deteriorated after $10 \mathrm{~h}$

Table 2

Composition of FeMo and FeMoP deposits obtained at different potentials over several substrates.

\begin{tabular}{|c|c|c|c|c|c|}
\hline \multirow[t]{2}{*}{ Electrolytic bath } & \multirow[t]{2}{*}{ Substrate } & \multirow[t]{2}{*}{$\mathrm{E} / \mathrm{V}$} & \multirow[t]{2}{*}{$\mathrm{q} / \mathrm{C} \mathrm{cm}^{-2}$} & \multicolumn{2}{|c|}{ Deposit composition } \\
\hline & & & & wt\% Mo & wt\% P \\
\hline \multirow[t]{6}{*}{ FeMo } & Copper & -1.8 & 100 & 55 & - \\
\hline & Graphite & & 100 & 48 & - \\
\hline & $\mathrm{Si} / \mathrm{Ti} / \mathrm{Cu}$ & & 100 & 58 & - \\
\hline & & & 1000 & 31 & \\
\hline & Steel & & 100 & 33 & \\
\hline & & & 500 & 48 & \\
\hline \multirow[t]{7}{*}{ FeMoP-1 } & Copper & -1.8 & 100 & 57 & 0.2 \\
\hline & & & 500 & 53 & 0.2 \\
\hline & & -1.5 & 100 & 53 & 0.1 \\
\hline & & & 500 & 48 & 0.1 \\
\hline & & -1.3 & 100 & 49 & 0.1 \\
\hline & & & 500 & 49 & 0.2 \\
\hline & $\mathrm{Si} / \mathrm{Ti} / \mathrm{Cu}$ & -1.8 & 100 & 49 & 0.2 \\
\hline \multirow[t]{10}{*}{ FeMoP-2 } & $\mathrm{Cu}$ & -1.8 & 100 & 56 & 0.4 \\
\hline & & & 500 & 55 & 0.4 \\
\hline & & -1.5 & 100 & 52 & 0.3 \\
\hline & & & 500 & 48 & 0.3 \\
\hline & & -1.3 & 100 & 47 & 0.4 \\
\hline & & & 500 & 47 & 0.4 \\
\hline & $\mathrm{Si} / \mathrm{Ti} / \mathrm{Cu}$ & -1.8 & 100 & 56 & 0.5 \\
\hline & & & 1000 & 33 & 0.5 \\
\hline & Steel & & 100 & 34 & 0.4 \\
\hline & & & 500 & 49 & 0.4 \\
\hline
\end{tabular}



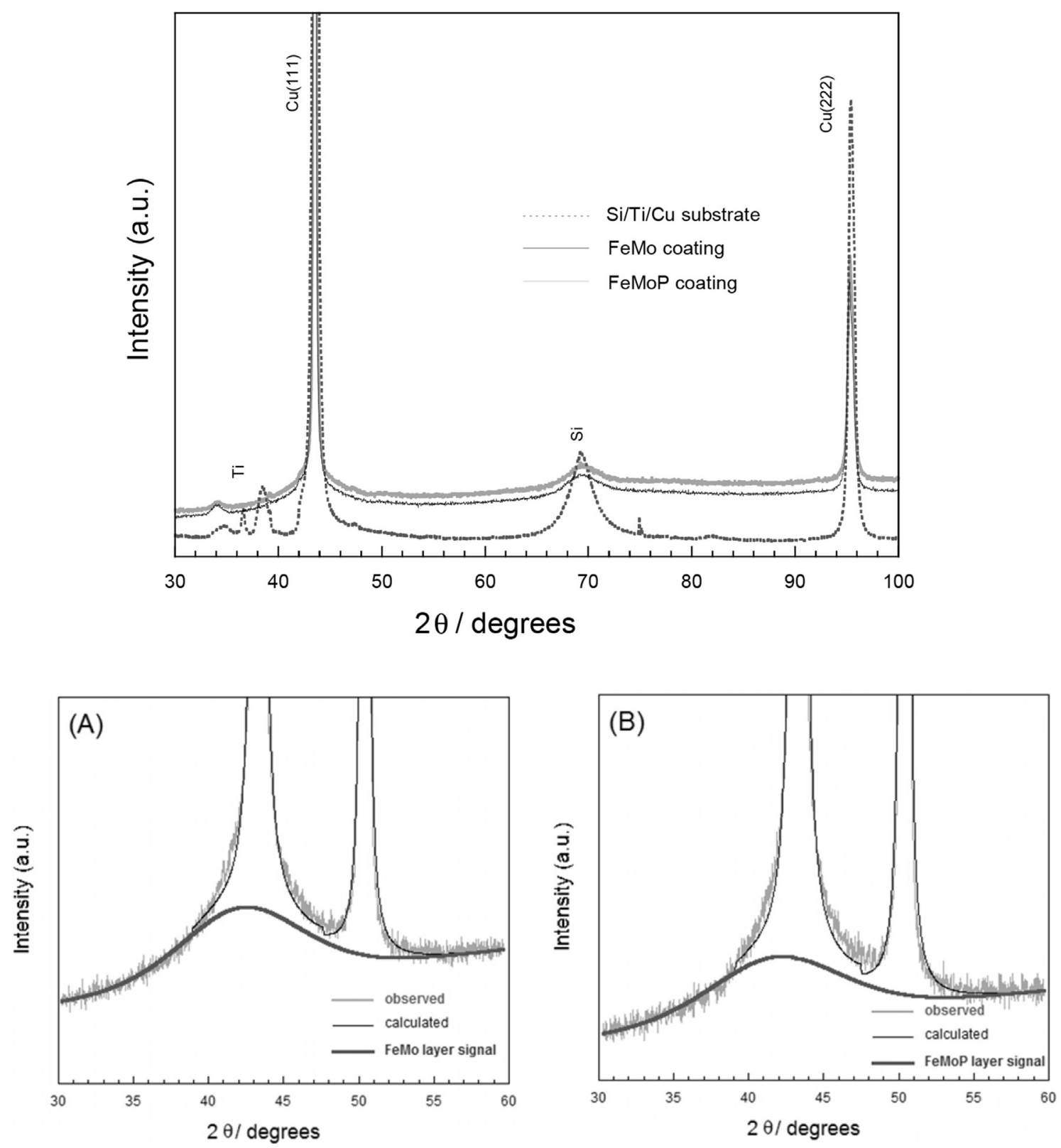

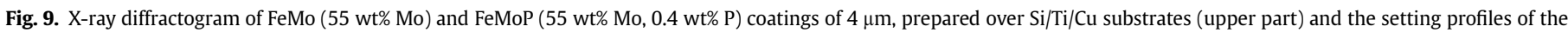
coatings obtained on copper substrates (lower part): (A) FeMo and (B) FeMoP coating.

immersion and breaks down at $48 \mathrm{~h}$ immersion, owing to the severe galvanic corrosion between deposits and the substrate [31].

Fig. 12 shows the EIS plots for the coatings with different immersion time in $\mathrm{Na}_{2} \mathrm{SO}_{4} 0.1 \mathrm{M}$. Nyquist diagram for FeMo coating (Fig. 12(a)) shows a gradual reduction of the diameter of capacitive arc with the immersion time, attributed to the decreased of the corrosion resistance. Bode $\phi$ versus log (f) diagrams show one time constant in the low frequency/middle frequency region with an average maximum at $\sim 0.6 \mathrm{~Hz}\left(-68^{\circ}\right)$, although the asymmetry of this plot indicates the presence of more than one time constant. On the contrary, the Nyquist diagrams of FeMoP coating show a gradual increase in the capacitive arc with immersion time until $24 \mathrm{~h}$, while the Bode diagram $\phi$ vs. $\log \mathrm{f}$ shows an increased in the phase angle $\sim 0.12 \mathrm{~Hz}\left(-59^{\circ}\right)$ to $\sim 0.12 \mathrm{~Hz}\left(-68^{\circ}\right)$ in the first hours of immersion (Fig. 13). This suggests that a passive film (corrosion products) is formed on the surface of the FeMoP coating during the initial immersion period, which improves the corrosion resistance, as it has been also detected in the potentiodynamic curves. It has been reported that a passive film consisting of oxides and hydroxides can be formed in ternary iron base electrodeposited [32], decreasing the corrosion rate. Therefore, the incorporation of $\mathrm{P}$ in the alloy really improves the durability of the coating. However, at long immersion time (48 h), Nyquist diagrams for both FeMo and FeMoP electrodeposited coatings show the characteristic diffusion behavior, and Bode diagrams show an asymmetrical response with a decreasing in the phase angle $\sim 49 \mathrm{~Hz}\left(-48^{\circ}\right)$, although the asymmetry of this plot indicates the presence of more than one time constant. The high-middle frequency time constant is attributable to the impedance in the porous of coating, while the lowmiddle frequency time constant can be related to the oxidation of 


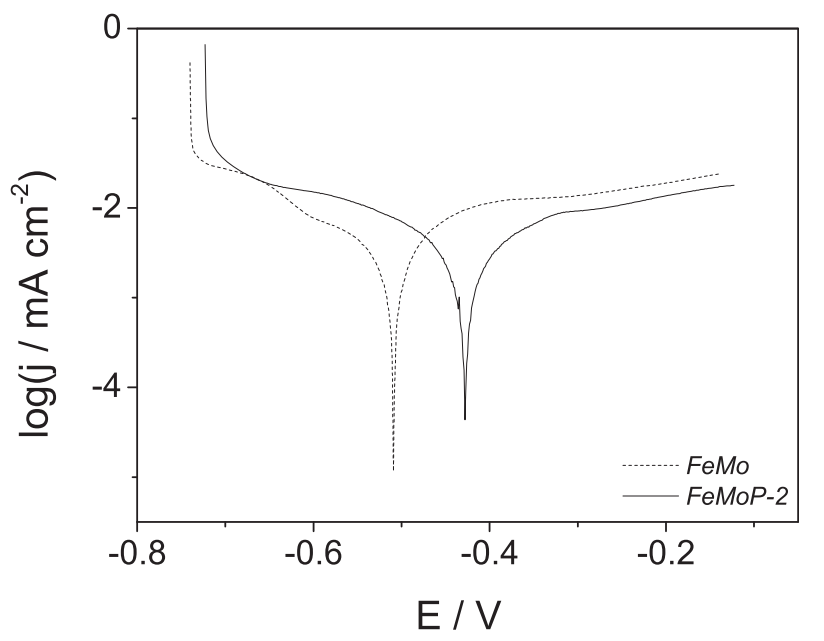

Fig. 10. Potentiodynamic curves in $0.1 \mathrm{M} \mathrm{Na}_{2} \mathrm{SO}_{4}$ solution at $0.1 \mathrm{mV} \mathrm{s}^{-1}$, in logarithmic format, of the FeMo and FeMoP coatings electrodeposited (at $-1.8 \mathrm{~V}, 100 \mathrm{Ccm}^{-2}$ ) in $\mathrm{FeMo}$ and $\mathrm{FeMoP}-2$ baths, respectively, on copper substrate.

Table 3

Corrosion parameters obtained from Fig. 10.

\begin{tabular}{lll}
\hline Coating & $\mathrm{E}_{\mathrm{corr}} / \mathrm{V}$ & $\mathrm{j}_{\mathrm{corr}} / \mu \mathrm{A} \mathrm{cm}^{-2}$ \\
\hline FeMo & -0.509 & 3.1 \\
FeMoP & -0.428 & 3.4 \\
\hline
\end{tabular}

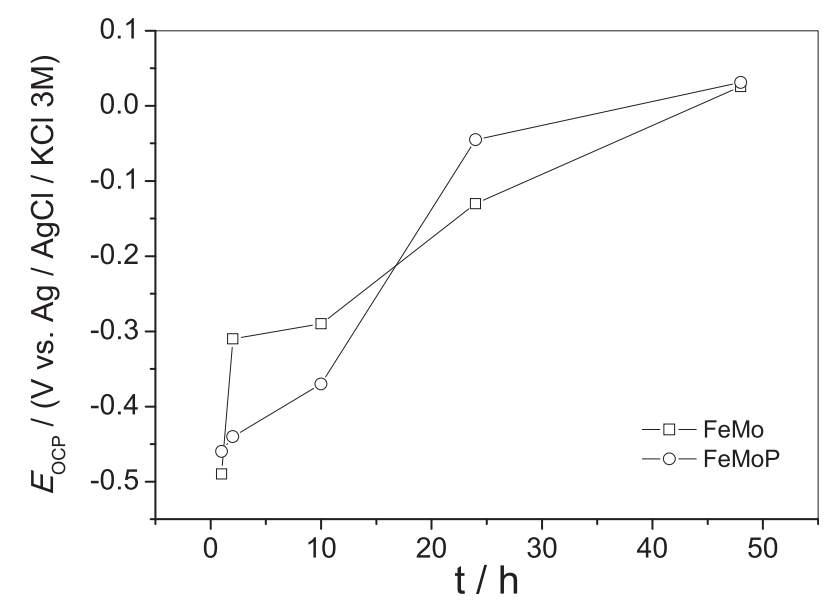

Fig. 11. Open circuit potential $v s$. time for deposits prepared over copper substrate at $-1.8 \mathrm{~V}$ in FeMo and FeMoP-1 baths, measured in aerated and unstirred $0.1 \mathrm{M} \mathrm{Na}_{2} \mathrm{SO}_{4}$ solution until $48 \mathrm{~h}$ of immersion at $25^{\circ} \mathrm{C}$.

metals from coating (corrosion process) [33], which implies that the passive film is now deteriorate and the electrolyte penetrates into the coating to interact with copper substrate.

Figs. 12 and 13 also show the fitting curves when the EIS results were analyzed using the electrical equivalent circuit (EEC) method, resulting the equivalent circuit shown in Fig. 14. Z-view ${ }^{\mathbb{R}}$ program was employed for quantitative analysis of the EIS responses. The circuit was chosen taking into account the structure of the samples and the best fitting for the experimental values, giving a lower residual error in each parameter of the equivalent circuit. The suitability of the proposed EEC was indicated by the sum of Chisquared deviations $\left(\chi^{2}\right)$ value around $10^{-3}$ with relative low standard errors $(<10 \%)$ of each parameter (Table 1 S Supplementary
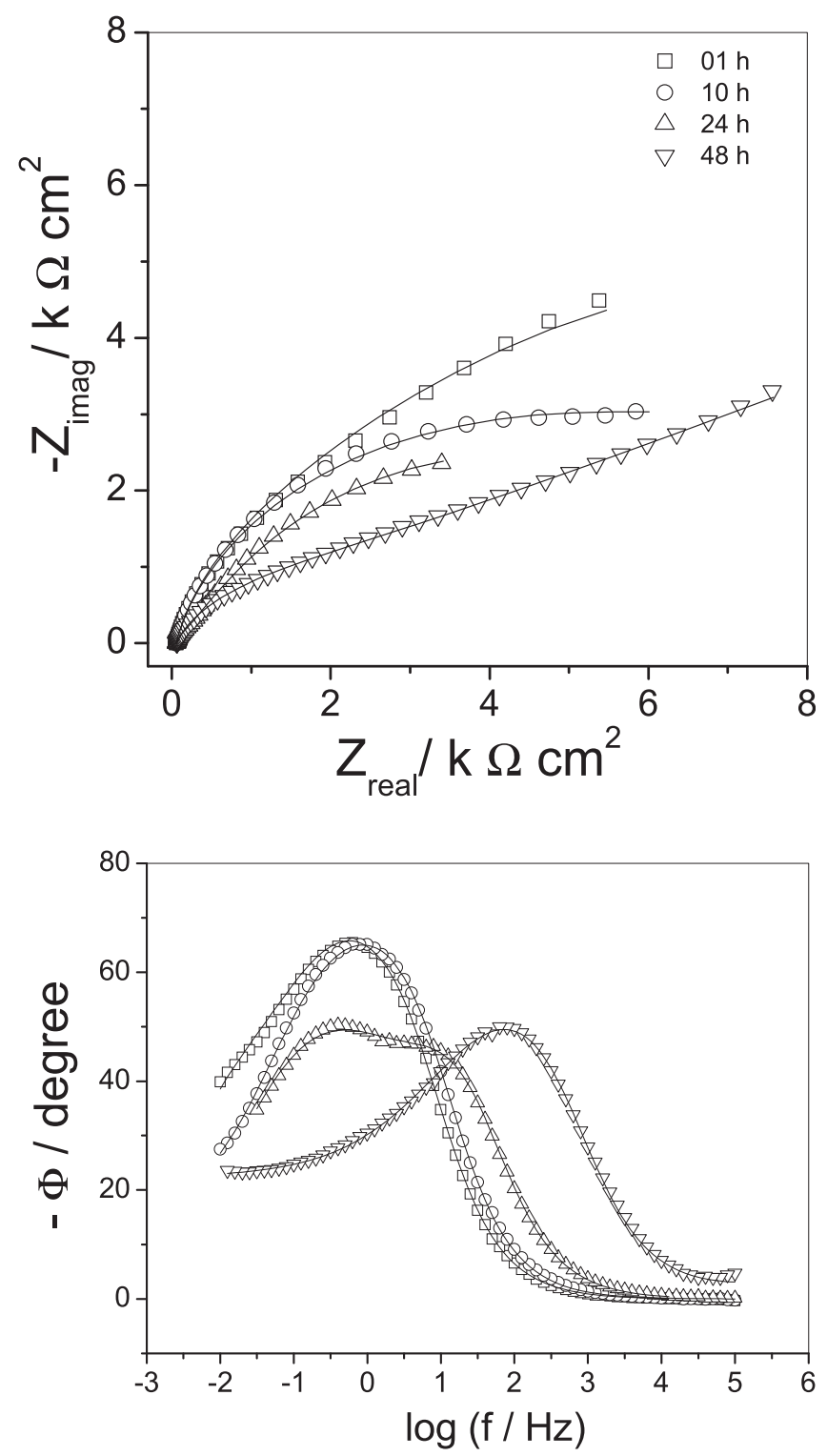

Fig. 12. (a) Experimental (symbol) and fitting (solid line) Nyquist and (b) Bode $-\phi$ versus $\log (\mathrm{f})$ plots for FeMo coatings $\left(-1.8 \mathrm{~V}, 100 \mathrm{Ccm}^{-2}\right)$ until $48 \mathrm{~h}$ of immersion in $0.1 \mathrm{M} \mathrm{Na}_{2} \mathrm{SO}_{4}$ solution at $25{ }^{\circ} \mathrm{C}$.

material), as well as the good agreement between the fitted and experimental EIS diagrams. The fitting was performed using an EEC similar to that previously suggested for electrodeposited coatings [31,33]. $R_{S}$ refers to the solution resistance, $C P E_{\text {coat }}$ and $C P E_{\mathrm{dl}}$ are used, respectively, as the coating's capacitance and the double layer capacitance originated by the electrochemical corrosion at sample surface [31]. $R_{\text {coat }}$ represents the resistance of the coating, and $R_{\mathrm{ct}}$ (charge transfer resistance) the resistance at the electron transfer during the electrochemical reaction.

For the analysis of corrosion resistance of the coatings, the $R_{\mathrm{ct}}$ values were plotted with the increase of the immersion time (Fig. 14). The FeMo coating shows a fast $R_{\mathrm{ct}}$ decrease in the initial $24 \mathrm{~h}$, due to its anodic dissolution. The FeMoP coating shows a $R_{\mathrm{ct}}$ almost stable until $24 \mathrm{~h}$ and the fast decrease occurred only after 48 of immersion. The analyses of EIS results showed that the two coatings were effective barrier for substrate protection and, for FeMoP coating, the formation of oxides on the surface leads to a greater barrier effect until $24 \mathrm{~h}$ of immersion time. These results are 

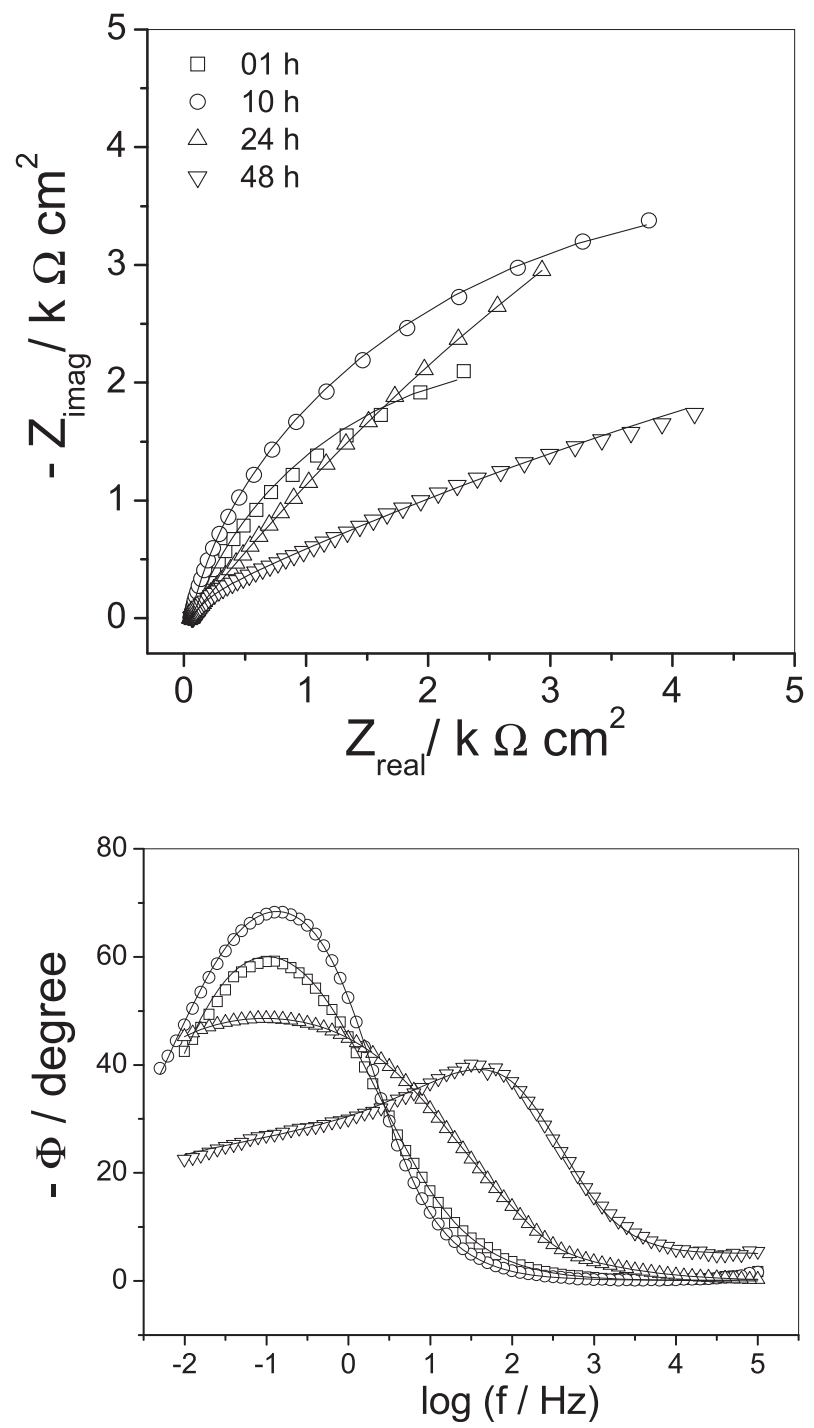

Fig. 13. (a) Experimental (symbol) and fitting (solid line) Nyquist and (b) Bode $-\phi$ versus $\log$ (f) plots obtained for FeMoP $\left(-1.8 \mathrm{~V}, 100 \mathrm{Ccm}^{-2}\right.$, FeMoP-1 bath) coatings until $48 \mathrm{~h}$ of immersion in $0.1 \mathrm{M} \mathrm{Na}_{2} \mathrm{SO}_{4}$ solution at $25^{\circ} \mathrm{C}$.

in agreement with others works that described that ternary iron base electrodeposits show better corrosion resistance than binary electrodeposits [32,33].

\section{Conclusions}

The electrodeposition using the NTA chelating agent allows the electrodeposition of the FeMo and FeMoP alloys by means of a stable environmentally friendly electrolytic bath, additives-free, in alkaline medium at room temperature. The study of the electrodeposition process allowed us to select the electrodeposition potentials leading to FeMo and FeMoP coatings over different substrates (copper, graphite, steel, $\mathrm{Si} / \mathrm{Ti} / \mathrm{Cu}$ ) as the manner that the bath is enough versatile to work over several materials. The bath used allows the induced co-deposition of iron and molybdenum, leading to significant molybdenum percentages (around $50 \mathrm{wt} \%$ ), and phosphorous incorporation ( $<1 \mathrm{wt} \%)$ in the form of compact, fine-grained deposits with amorphous structure and promising corrosion resistance. The low variation of the composition as a function of the substrate, charge density and potential
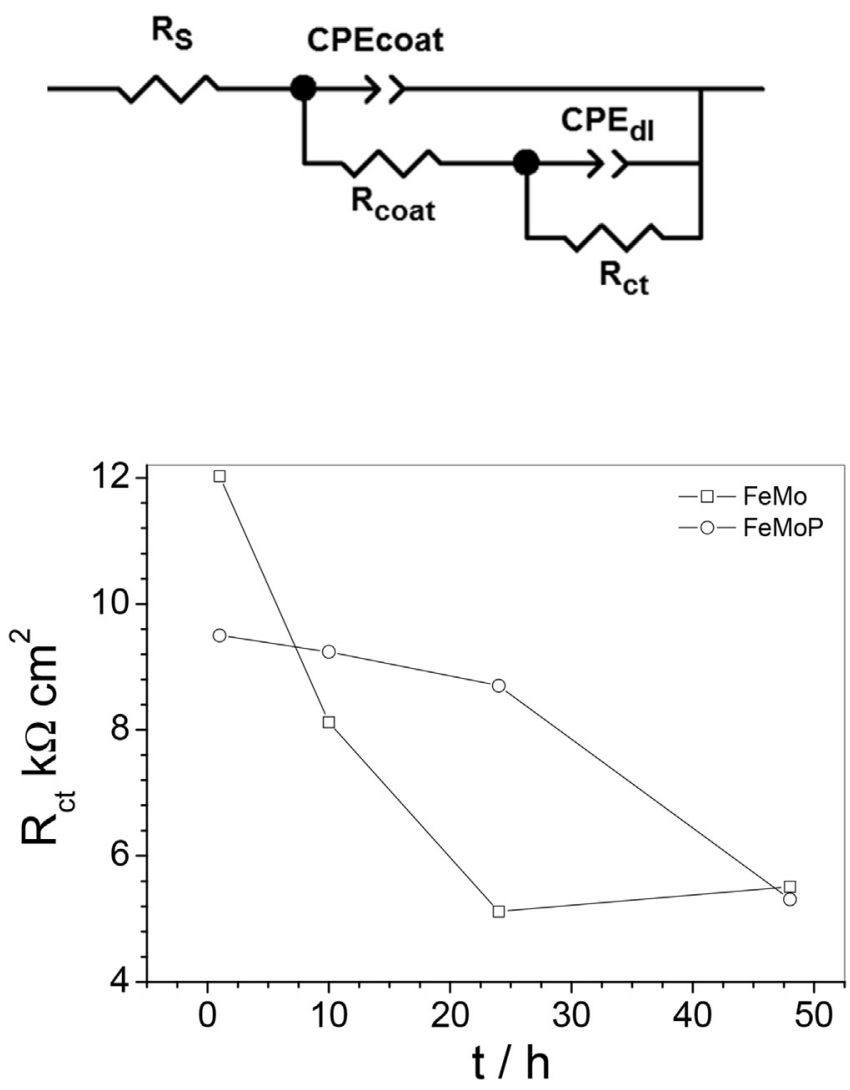

Fig. 14. Electrical equivalent circuit used to fit the EIS data of Figs. 12 and 13 and resulting $R_{\mathrm{CT}}$ values.

demonstrates the promising industrial usability of the developed bath. Non stirring conditions are required because the composition maintains with the thickness of the deposits. Although the P percentage in the deposits is low, its presence significantly improves the performance of the protective coating by favouring the compactness of the films and the formation of passivating layer that hinders the generalized corrosion.

\section{Acknowledgements}

This work was supported by the EU ERDF (FEDER) funds and the Spanish Government grant TEC2014-51940-C2-2-R from Ministerio de Economía y Competitividad. The authors thank the CCiT-UB for the use of their equipment. E.P.Barbano is grateful to the Fundação de Amparo à Pesquisa do Estado de São Paulo (FAPESP) by the grant 2015/21788-0.

\section{Appendix A. Supplementary data}

Supplementary data related to this article can be found at http:// dx.doi.org/10.1016/j.jallcom.2016.10.208.

\section{References}

[1] L. Shunning, L. Baixin, L. Jianbo, First principles study of structural stability and magnetic property of non-equilibrium Co-Mo alloys, Acta Metall. Sin. (Engl. Lett.) 27 (2014) 1057-1062.

[2] A. Brenner, Electrodeposition of Alloys: Principles and Practice, vol. 1, Academic Press, New York, 1963.

[3] N.R. Elezović, V.D. Jović, N.V. Krstajić, Kinetics of the hydrogen evolution reaction on Fe-Mo film deposited on mild steel support in alkaline solution, Electrochim. Acta 50 (2005) 5594-5601.

[4] N.R. Elezovic, B.N. Grgur, N.V. Krstajic, V.D. Jovic, Electrodeposition and 
characterization of Fe-Mo alloys as cathodes for hydrogen evolution in the process of chlorate production, J. Serbian Chem. Soc. 70 (2005) 879-889.

[5] E.J. Podlaha, D. Landolt, Induced codeposition. I. An experimental investigation of Ni-Mo alloys, J. Electrochem. Soc. 144 (1996) 885-892.

[6] D.W. Ernest, R.F. Amlie, M.L. Holt, Electrodeposition of molydenum alloys from aqueous solutions, J. Electrochem. Soc. 102 (1995) 461-469.

[7] Z.J. Niu, S.B. Yao, S.M. Zhou, In situ surface Raman investigation on inducedcodeposition of an Fe - Mo alloy, J. Electroanal. Chem. 455 (1998) 205-207.

[8] E. Gomez, E. Pellicer, E. Vallés, Detection and characterization of molybdenum oxides formed during the initial stages of cobalt-molybdenum electrodeposition, J. Appl. Electrochem 33 (2003) 245-252.

[9] A. Molinar, F. Marchetti, F.G. Strtielini, Aes study of ion-nitrided Fe-Mo and FeMo-P P/M alloys, Scr. Metall. Iidahdia 33 (6) (1995) 871-876.

[10] C. Lindberg, A New Fe-Mo-P Sintered Steel with Extremely High Impact Strength, Advances in Powder Metallurgy and Particulate Materials, vol. 2, Metal Powder Industries Federation, Princeton, NJ, 1992, pp. 99-106 compiled by Joseph M. Capus and Randall M. German.

[11] N. Fukumuro, J. Nishiyama, K. Shigeta, Y. Moritomo, H. Takagami, S. Yae, H. Matsuda, Co-P multilayer film electrodeposited under DC electrolysis, Electrochem. Commun. 9 (5) (2007) 1185-1188.

[12] I. Kosta, M. Sarret, C. Müller, Structure, microhardness and corrosion behaviour of nanostructured CoP coatings obtained by direct current and pulse plating, Electrochim. Acta 114 (2013) 819-826.

[13] R.D. Diegle, N.R. Sorenson, T. Tsuru, R.M. Latanision, The Corrosion Resistance of Glassy Alloys. Corrosion: Aqueous Processes and Passive Films, vol. 23, 1983, pp. 59-102.

[14] C.A.C. Sequeira, D.M.F. Santos, P.S.D. Brito, Electrocatalytic activity of simple and modified FeeP electrodeposits for hydrogen evolution from alkaline media, Energy 36 (2011) 847-853.

[15] A. Mikó, R. Hempelmann, M. Lakatos-Varsányi, E. Kálmán, Iron-Phosphorous layers deposited by pulse electrochemical technique, Electrochem. Solid-State Lett. 9 (8) (2006) 126-130.

[16] J.-L. Li, Y.-X. Zhang, C.-W. Liu, Q.-M. Zhu, Improvement in reactivity, reproducibility and stability of Fe-Mo catalysts by wet mixing, Catal. Today 51 (1999) 195-199.

[17] N.R. Elezovic, V.D. Jovic, N.V. Krstajic, Kinetics of the hydrogen evolution reaction on $\mathrm{Fe}-\mathrm{Mo}$ film deposited on mild steel support in alkaline solution, Electrochim. Acta 50 (2005) 5594-5601.

[18] A.V. Karakurkchi, M.V. Ved', N.D. Sakhnenko, I.Yu. Yermolenko, Electrodeposition of iron-molybdenum-tungsten coatings from citrate electrolytes, Russ. J. Appl. Chem. 88 (2015) 1860-1869.

[19] V.V. Kuznetsov, K.E. Golyanin, T.V. Pshenichkina, B.F. Lyakhov, S.E. Lyashenko, Chemical composition of Fe-Mo alloys obtained by electrodeposition, Mendeleev Commun. 23 (2013) 331-333.
[20] M.V. Ved', N.D. Sakhnenko, A.V. Karakurchi, S.I. Zyubanova, Electrodeposition of iron-molybdenum coatings from citrate electrolyte, Russ. J. Appl. Chem. 87 (3) (2014) 276-282.

[21] L.S. Sanches, S.H. Domingues, A. Carubelli, L.H. Mascaro, Electrodeposition of $\mathrm{Ni}-\mathrm{Mo}$ and Fe-Mo alloys from sulfate-citrate acid solutions, J. Braz. Chem. Soc. 14 (4) (2003) 556-563.

[22] E.P. Barbano, M.F. de Carvalho, I.A. Carlos, Electrodeposition and characterization of binary Fe-Mo alloys from trisodiumnitrilotriacetate bath, J. Electroanal. Chem. 775 (2016) 146-156.

[23] E.P. Barbano, I.A. Carlos, Estudo de um banho alcalino para a eletrodeposição de Fe-Mo-P, in: XXI Congresso da Sociedade Ibero-Americana de Eletroquímica (XXI -SIBAE), La Serena, Chile, 2014.

[24] G.M. de Oliveira, L.L. Barbosa, R.L. Broggi, I.A. Carlos, Voltammetric study of the influence of EDTA on the silver electrodeposition and morphological and structural characterization of silver films, J. Electroanal. Chem. 578 (2005) $151-158$.

[25] Barbosa L.L., Desenvolvimento e caracterizaçãoeletroanalítica e espectrofotométrica de banhos alcalinos, na presença de glicerol, sorbitol e EDTA para eletrodeposição de ligas de $\mathrm{Fe} / \mathrm{Zn}$ e caracterização química, física e morfológica dos filmes de Fe/Zn (Ph. D. Thesis Supervisor I. A. Carlos), University Federal of São Carlos, Department of Chemistry, 2005.

[26] M.R.H. de Almeida, E.P. Barbano, M.F. de Carvalho, I.A. Carlos, J.L.P. Siqueira, L.L. Barbosa, Electrodepositionofcopper-zincfromanalkalinebathbasedonEDTA, Surf. Coat. Technol. 206 (2011) 95-102.

[27] MEDUSA-chemical Diagrams (2.0) and HYDRA-Hydrochemical Database (2.0) Softwares of I. Puigdomenech. http://www.kemi.kth.se/medusa/.

[28] W.S. Tait, An Introduction to Electrochemical Corrosion Testing for Practicing Engineers and Scientists, 1994. Wisconsin Pair Odocs.

[29] E. Gómez, E. Pellicer, E. Vallés, Detection and characterization of molybdenum oxides formed during the initial stages of cobalt-molybdenum electrodeposition, J. Appl. Electrochem 33 (2003) 245-252.

[30] G. Tansuğ, T. Tüken, E.S. Giray, G. Findikkiran, G. Siğircik, O. Demirkol, M. Erbil A new corrosion inhibitor for copper protection, Corros. Sci. 84 (2014) 21-29.

[31] S.H. Wang X.W. Guo, C. Sun, J. Gong L.M. Peng W. Ding Electrodeposition of $\mathrm{Cu}$ coating with high corrosion resistance on Mg-3.0Nd-0.2Zn-0.4Zr magnesium alloy, Trans. Nonferrous Met. Soc. China 24 (2014) 3810-3817 (English Ed.

[32] G. Yar-mukhamedova, M. Ved, N. Sakhnenko, A. Karakurkchi, Iron binary and ternary coatings with molybdenum and tungsten, Appl. Surf. Sci. 383 (2016) 346-352.

[33] J. Winiarski, W. Tylus, M.S. Krawczyk, B. Szczygie, The in fl uence of molybdenum on the electrodeposition and properties of ternary $\mathrm{Zn}-\mathrm{Fe}-\mathrm{Mo}$ alloy coatings, Electrochim. Acta 196 (2016) 708-726. 